\title{
Determinação da área mínima de aterros sanitários para uso nos próximos 25 anos da microrregião Chapecó-SC
}

\author{
Determination of the minimum area of sanitary landfills for use in the next 25 years in the \\ Chapecó-SC microregion \\ Determinación del área mínima de rellenos sanitarios a utilizar en los próximos 25 años en la \\ microrregión Chapecó-SC
}

Recebido: 24/08/2021 | Revisado: 29/08/2021 | Aceito: 01/09/2021 | Publicado: 05/09/2021

Lucas Menezes Felizardo

ORCID: https://orcid.org/0000-0002-9676-0623 Universidade Estadual Paulista “Júlio de Mesquita Filho", Brasil

E-mail: lucas.felizardo@unesp.br

Mauricio Santini Junior

ORCID: https://orcid.org/0000-0002-7208-1108 Universidade Estadual Paulista "Júlio de Mesquita Filho", Brasil E-mail: santini.mauricio@ifsp.edu.br

Glaucia Amorim Faria

ORCID: https://orcid.org/0000-0003-2474-4840 Universidade Estadual Paulista "Júlio de Mesquita Filho", Brasil

E-mail:glaucia.a.faria@unesp.br

Jefferson Nascimento de Oliveira ORCID: https://orcid.org/0000-0002-4453-6347 Universidade Estadual Paulista “Júlio de Mesquita Filho", Brasil E-mail: jefferson.nascimento@unesp.br

Diego Javier Pérez Ortega ORCID: https://orcid.org/0000-0003-3591-5166 Universidad Cooperativa de Colombia, Colômbia

E-mail: diegojavierperez77@hotmail.com

Gilberto Coelho

ORCID: https://orcid.org/0000-0002-0654-2754 Universidade Federal de Lavras, Brasil E-mail: coelho@ufla.br

Kátia Luciene Maltoni

ORCID: https://orcid.org/0000-0001-6619-4504 Universidade Estadual Paulista "Júlio de Mesquita Filho", Brasil

E-mail: katia.maltoni@unesp.br

\begin{abstract}
Resumo
Este presente trabalho teve como objetivo demonstrar um método para se obter o tamanho mínimo de um aterro sanitário com base no crescimento da população no atual cenário de desenvolvimento econômico do Brasil. Usando como base metodológica curvas logísticas com a estimativa do crescimento da população, projeção de resíduos coletados pelo modelo SGompertz e com estimativas da produção de resíduos sólidos urbanos (RSU) dos municípios da microrregião Chapecó nos anos de 2021 a 2045, como forma a determinar a área necessária para disposição final desses RSUs, encontrando áreas necessárias para implantação de aterros partindo de $819 \mathrm{~m}^{2}$ chegando a aproximadamente $500 \mathrm{mil} \mathrm{m}^{2}$ como no caso de Chapecó a maior cidade da região. O conhecimento da área mínima do aterro é de grande importância para os municípios organizarem suas políticas de gestão e para planejamentos de suas políticas de RSUs.
\end{abstract}

Palavras-chave: Gestão de RSUs; Censo IBGE 2010; Lei Nº12.305/2010.

\begin{abstract}
This present work aimed to demonstrate a method to obtain the minimum size of a landfill based on population growth in the current scenario of economic development in Brazil. Using as methodological basis logistic curves with estimated population growth, projection of waste collected by the SGompertz model and with estimates of the production of urban solid waste (USW) of municipalities in the Chapecó microregion in the years 2021 to 2045 , as a way to determine the area necessary for the final disposal of these USW, finding areas necessary for the implementation of landfills starting from $819 \mathrm{~m}^{2}$ reaching approximately 500 thousand $\mathrm{m}^{2}$ as in the case of Chapecó, the largest city in the region. The knowledge of the minimum landfill area is of great importance for municipalities to organize their management policies and for planning their USW policies.
\end{abstract}


Keywords: Management of solid waste urban; IBGE census 2010; Law N¹2.305/2010.

\section{Resumen}

El presente trabajo tuvo como objetivo demostrar un método para obtener el tamaño mínimo de un relleno sanitario basado en el crecimiento de la población en el escenario actual de desarrollo económico en Brasil. Utilizando como base metodológica curvas logísticas con crecimiento poblacional estimado, proyección de residuos recolectados por el modelo SGompertz y con estimaciones de la producción de residuos sólidos urbanos (RSU) de los municipios de la microrregión Chapecó en los años 2021 a 2045, como forma de determinar el área necesaria para la disposición final de estas RSU, encontrando áreas necesarias para la implementación de rellenos sanitarios a partir de $819 \mathrm{~m}^{2}$ llegando aproximadamente a $500 \mathrm{mil} \mathrm{m}^{2}$ como en el caso de Chapecó, la ciudad más grande de la región. El conocimiento de la superficie mínima del vertedero es de gran importancia para que los municipios organicen sus políticas de gestión y planifiquen sus políticas de RSU.

Palabras clave: Gestión de RSU; Censo IBGE 2010; Ley Nº12.305/2010.

\section{Introdução}

Os moldes da população como conhecemos hoje é de uma sociedade que é grande produtora de lixo, esse que tem um odor desagradável, atrai insetos e suja as cidades, constituído pelas coisas que as pessoas não querem mais, por isso grande parte da população não se preocupa com seu destino, isso vem mudando nos últimos anos com o desenvolvimento sócio, econômico e cultural dos brasileiros e algumas iniciativas já vêm sendo colocadas em prática como a coleta seletiva e o fechamento dos lixões. (Silva, 2017)

Com o desenvolvimento econômico vem se notando o aumento dos resíduos sólidos urbanos (RSU) em uma proporção maior do que o crescimento populacional, no Brasil hoje é produzido $378 \mathrm{Kg}$ habitante/ano e à medida que o país cresce economicamente a tendência é de um incremento na produção de RSU. (Dziekaniak, 2014).

Em agosto de 2010 foi sancionada a lei $\mathrm{n}^{\circ} 12.305$, que institui a política nacional de resíduos sólidos, o marco regulatório do setor. A lei estabelece a distinção entre resíduo, que é o lixo reciclável, e rejeito que não pode ser reaproveitado e faz a classificação dos tipos de detritos (doméstico, industrial, eletrônico, da construção civil, da área de saúde, etc.), (Picchiai \& Senigalia, 2019). Uma de suas determinações é que se dê tratamento adequado a cada tipo de lixo e que se intensifique a reciclagem, com ênfase na logística reversa: o próprio fornecedor recebe de volta o material descartado e o reutiliza como já acontece no caso de pilhas e baterias de celulares. (Peron, 2019)

A lei $\mathrm{N}^{\circ} 12.305 / 2010$ proíbe a criação de Lixões - todas as prefeituras do país teriam de construir até 2014 aterros sanitários ambientalmente sustentáveis em que só poderão ser depositados resíduos sem possibilidade de reaproveitamento, prazo que vem sendo ampliado desde então sem ocorrer as sanções previstas pela lei.

Encontrar a solução adequada para a disposição final dos resíduos sólidos de uma cidade é essencial para a questão do meio ambiente, do saneamento e da saúde pública, porém não é o suficiente. Os resíduos sólidos devem ser gerenciados adequadamente de forma integrada, desde sua origem até a disposição final, abordando a minimização ou redução da quantidade gerada, a reciclagem e a reutilização ou reaproveitamento de materiais (Jacobi \& Besen, 2011).

$\mathrm{O}$ aterro sanitário tem o objetivo de confinar a menor quantidade de resíduos que seja possível em um terreno com determinadas garantias de impermeabilização, com a adoção de procedimentos para proteção do meio ambiente, evitando a contaminação dos solos naturais e efetuando sua cobertura definitiva, obtendo-se ao final um espaço verde, um local para o lazer ou programas habitacionais (Silva, 2016).

Nesse cenário esse artigo veio para apresentar uma das primeiras etapas para implantação de um aterro sanitário seguindo as normas definidas pela Associação Brasileira de Normas Técnicas (ABNT) com o estabelecimento da área mínima necessária para sua construção de modo a absorver a produção de resíduos sólidos urbanos de cidades da microrregião de Chapecó por um período mínimo de 25 anos. 


\section{Metodologia}

Para este estudo de caso (Pereira, 2018) o local selecionado foi a microrregião de Chapecó, que é uma das microrregiões do estado brasileiro de Santa Catarina pertencente à mesorregião Oeste Catarinense. Sua população foi estimada em 2010 pelo IBGE em 405.066 habitantes e está dividida em 38 municípios. Possui uma área total de 6.045,917km².

Figura 1- Microrregião Chapecó no oeste catarinense.

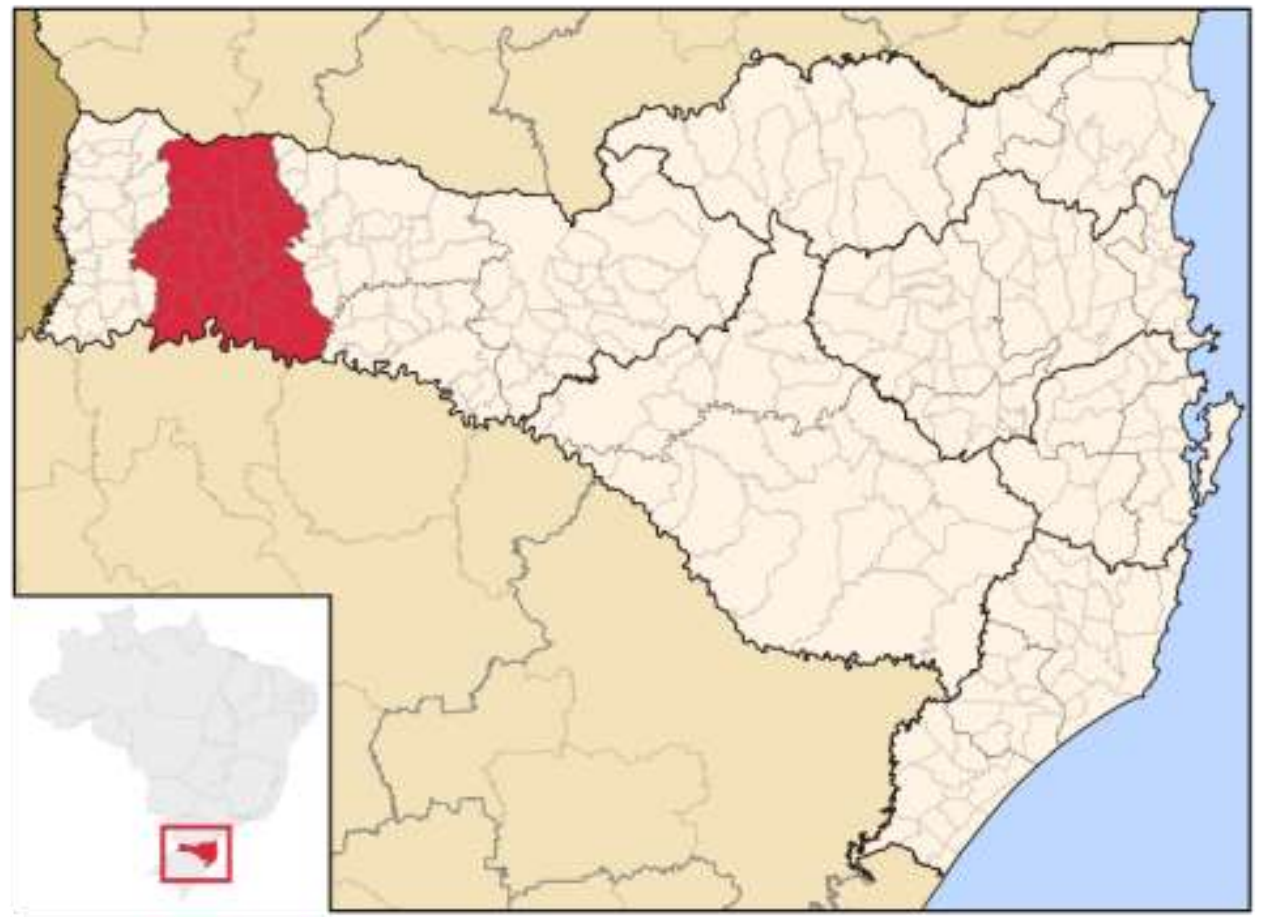

Fonte: Adaptado Google Imagens.

Para determinar a população em cada ano do período analisado (2021-2045) foi utilizado os dados dos CENSOS 2000 e 2010. O número de habitantes foi projetado ano a ano pelo método geométrico de crescimento, seguindo as seguintes equações:

$$
\begin{gathered}
K g=\frac{\operatorname{Ln}\left(P_{2010}\right)-\operatorname{Ln}\left(P_{2010}\right)}{2010-2000} \\
P_{i}=P_{2010} \times e^{K g(i-2010)}
\end{gathered}
$$

Onde, P é a população no ano i

Então, a porcentagem da população urbana foi determinada para cada ano e cidade, a partir da determinação do padrão de crescimento da população urbana no Brasil com o auxílio dos dados dos CENSOS 1950, 1960, 1970, 1980, 1991, 2000 e 2010, foi ajustada uma curva parametrizada do tipo logística ( $\mathrm{R}=99,9 \%)$. A morfologia dessa curva foi replicada para o atual estágio de urbanização de cada cidade, podendo ser verificada na Figura 2.

Curva Projetada:

$$
y=0,36321+\frac{1,0196-0,36321}{1+\left(\frac{x}{32,18076}\right)^{1,66342}}
$$


Figura 2 - Projeção de população urbana ao longo do tempo.

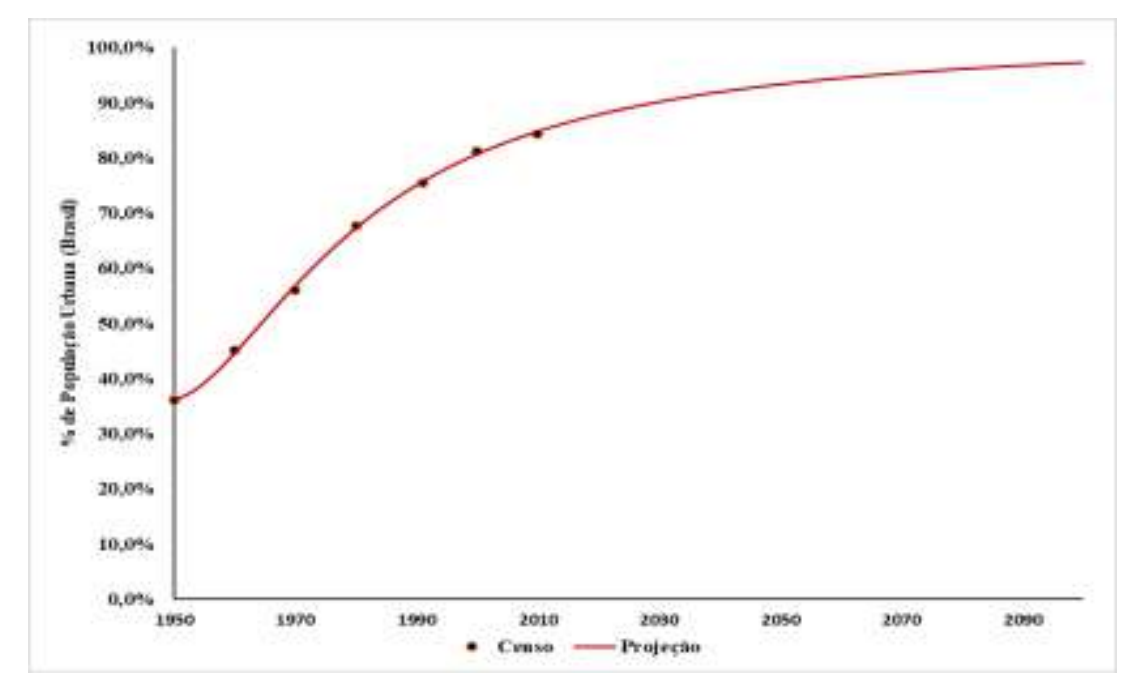

Fonte: Autores.

A curva representa um comportamento assintótico em $100 \%$ de coleta de resíduo sólidos, situação que ocorre com a implementação cada vez mais universal da coleta de resíduos sólidos, sendo apresentado a curva na Figura 3.

Curva Projetada: $y=0,99477 \times e^{-e^{(-0,09241 \times(x-1982,86))}}$

Figura 3 - Projeção da coleta de RSU ao longo dos anos.

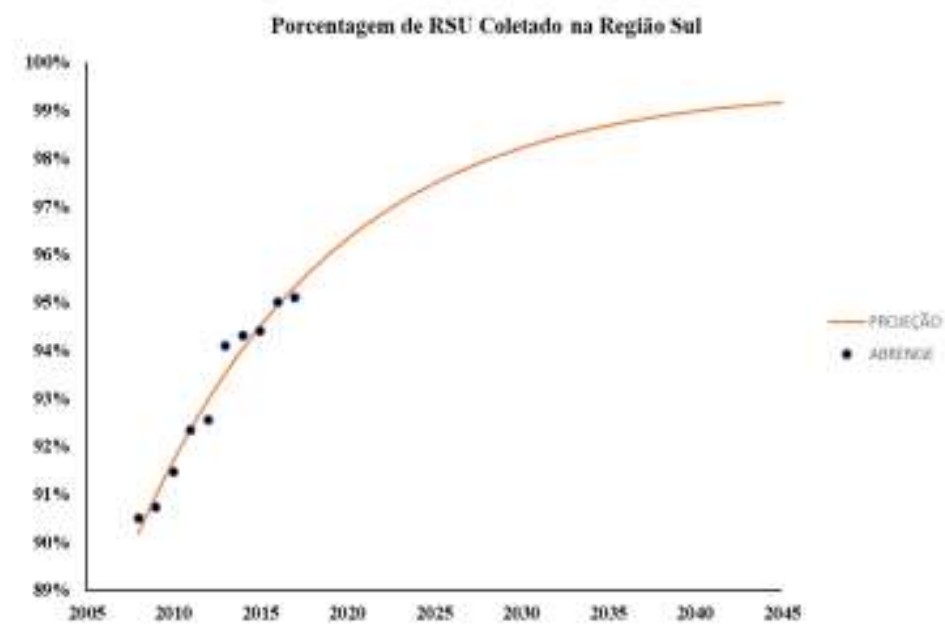

Fonte: Autores.

Calculou-se a estimativa de RSU coletado a cada ano na região sul do Brasil. Para isso, foi ajustado uma curva do tipo SGompertz com os dados da ABRELPE 2008, ABRELPE 2009, ABRELPE 2010, ABRELPE 2011, ABRELPE 2012, ABRELPE 2013, ABRELPE 2014, ABRELPE 2015, ABRELPE 2016, ABRELPE 2017 os valores foram expressos ano a ano como pode ser verificado na Tabela 1 . 
Tabela 1 - Estimativa de RSU coletado na região Sul ao longo dos anos.

\begin{tabular}{rrrrrrrrrrrrrr}
\hline Ano & $\mathbf{2 0 2 1}$ & $\mathbf{2 0 2 2}$ & $\mathbf{2 0 2 3}$ & $\mathbf{2 0 2 4}$ & $\mathbf{2 0 2 5}$ & $\mathbf{2 0 2 6}$ & $\mathbf{2 0 2 7}$ & $\mathbf{2 0 2 8}$ & $\mathbf{2 0 2 9}$ & $\mathbf{2 0 3 0}$ & $\mathbf{2 0 3 1}$ & $\mathbf{2 0 3 2}$ & $\mathbf{2 0 3 3}$ \\
CL & $96,6 \%$ & $96,8 \%$ & $97,1 \%$ & $97,3 \%$ & $97,5 \%$ & $97,6 \%$ & $97,8 \%$ & $98,0 \%$ & $98,1 \%$ & $98,2 \%$ & $98,3 \%$ & $98,4 \%$ & $98,5 \%$ \\
Ano & $\mathbf{2 0 3 4}$ & $\mathbf{2 0 3 5}$ & $\mathbf{2 0 3 6}$ & $\mathbf{2 0 3 7}$ & $\mathbf{2 0 3 8}$ & $\mathbf{2 0 3 9}$ & $\mathbf{2 0 4 0}$ & $\mathbf{2 0 4 1}$ & $\mathbf{2 0 4 2}$ & $\mathbf{2 0 4 3}$ & $\mathbf{2 0 4 4}$ & $\mathbf{2 0 4 5}$ \\
CL & $98,6 \%$ & $98,7 \%$ & $98,7 \%$ & $98,8 \%$ & $98,9 \%$ & $98,9 \%$ & $99,0 \%$ & $99,0 \%$ & $99,1 \%$ & $99,1 \%$ & $99,1 \%$ & $99,2 \%$ \\
\hline
\end{tabular}

Fonte: Autores.

Segundo ABRELPE, 2008 a 2017, a produção de RSU per capita na região sul é uma variável sem tendência nítida de aumento ou decréscimo ao longo do tempo, variando em torno de um valor médio, conforme se observa na Figura 4. Destarte, neste trabalho, foi utilizado o valor médio de produção de RSU per capita.

$$
C=0,80527\left(\frac{\frac{K g}{h a b}}{D i a}\right)
$$

Figura 4 - Evolução da geração de RSU per capita ao longo dos anos.

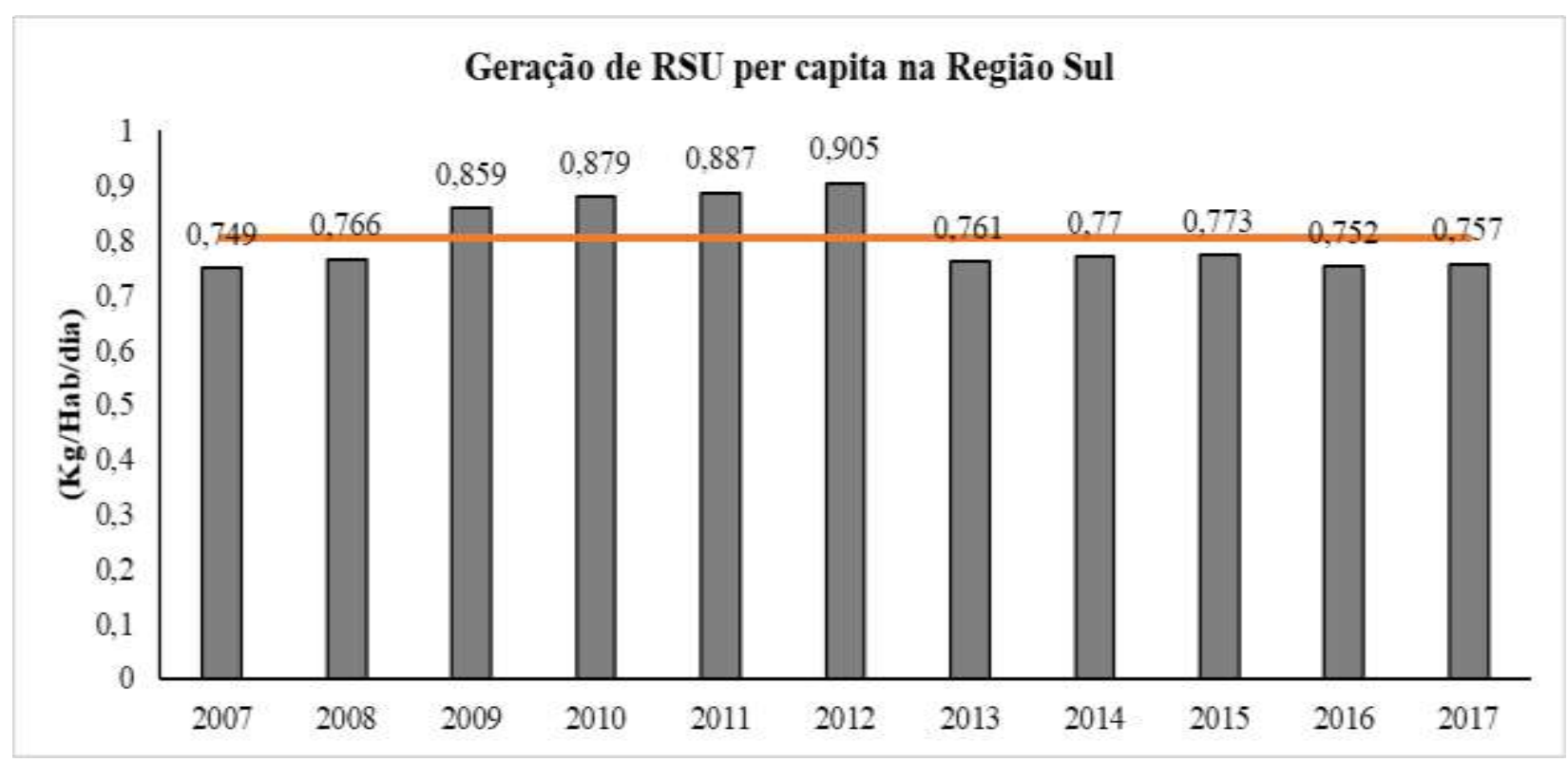

Fonte: Autores.

Com todas as variáveis determinadas ano a ano, foi aplicada a equação a seguir para determinar a massa de RSU gerado no período analisado.

$$
M(K g)=\sum_{i=2011}^{2045}\left(C \times 365 \times C L_{i} \times P o p_{i} \times U R B_{i}\right)
$$

Onde:

M é a massa gerada no período de 2011 até 2045, em Kg;

C é a geração de RSU per capitada (Kg/hab/dia);

$C L_{i}$ é a porcentagem de coleta de RSU no ano i;

$P o p_{i}$ é a população no ano i (Hab)

$U R B_{i}$ é a porcentagem de urbanização no ano i. 
A determinação da área mínima do aterro foi calculada segundo a equação a seguir.

$$
\text { Amin }=\frac{M}{d . h} \times(1-\rho)
$$

Onde, Amin é a área mínima em $\mathrm{m}^{2}$;

M é a massa de RSU gerado no período em $\mathrm{Kg}$;

d é a massa específica do RSU compactado em $\mathrm{Kg} / \mathrm{m}^{3}$

$\mathrm{h}$ é a altura projetada do aterro em $\mathrm{m}$;

$\rho$ é o recalque na massa de resíduos após sua decomposição.

Segundo HADDAD (1999) o peso dos resíduos sólidos varia entre 500 e $700 \mathrm{~kg} \mathrm{~m}^{3}$, para esse trabalho, usamos o limite inferior de $500 \mathrm{Kg} / \mathrm{m}^{3}$. Não existe altura padrão para a construção de aterros, porém, as células não costumam ultrapassar os 6 metros de altura, uma vez que alturas excessivas dificultam a operação, como a subida dos tratores. Portanto, para esse trabalho foi utilizado $\mathrm{h}=6$ metros.

Com o passar do tempo, o RSU vai sofrendo decomposição e diminuindo de volume, segundo estudos podemos admitir um percentual de recalque de 30\% no final da utilização do aterro (Silva, 2016; Denardin, 2013; Russo, 2006).

A Figura 5 mostra a proposta metodológica para este trabalho.

Figura 5 - Metodologia do trabalho.

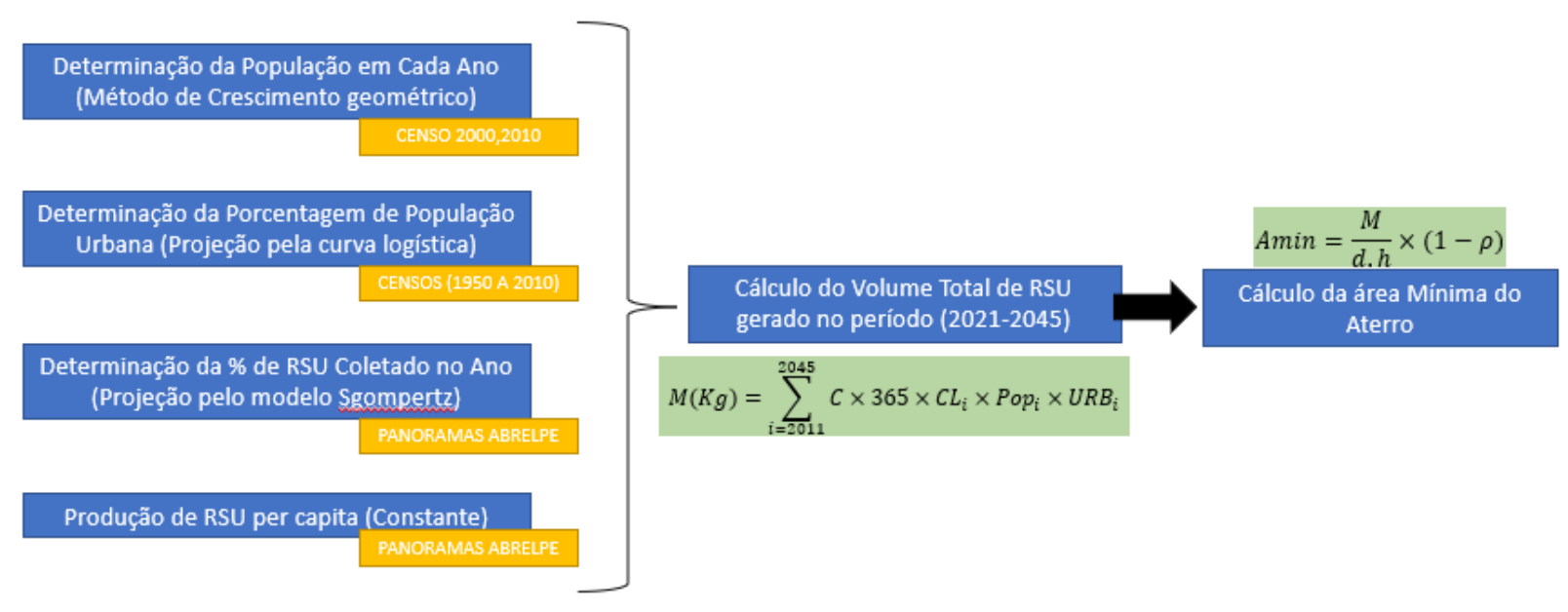

Fonte: Autores.

\section{Resultados e Discussão}

Com a entrada em vigor da Lei N $12.305 / 2010$ todos os municípios do Brasil teriam que ter um local adequado para a disposição final de seus resíduos sólidos urbanos já em 2014, para isso seria necessário saber as necessidades de cada município, para determina as melhores maneiras para uma gestão bem-sucedida do empreendimento que é o Aterro Sanitário seguindo todas as normas técnicas. (Souza, 2002; Jucá, 2003)

Alguns municípios do oeste catarinense não têm como manter um aterro sanitário seguindo as normas da $\mathrm{ABNT}$, seja por não ter em seu município um local que concentre todas as características adequadas para sua implantação ou por não ter recursos suficientes. (Meireles, 2012)

$\mathrm{Na}$ Tabela 2 é apresentado o resultado referente a equações adotadas nesse trabalho. 
Tabela 2 - Aqui são apresentadas as cidades com as estimativas de RSU coletados em 25 anos em megagrama e a área mínima em metros quadrados.

\begin{tabular}{|c|c|c|}
\hline Cidades & Massa total (Mg) & Área mínima $\left(m^{2}\right)$ \\
\hline Águas de Chapecó & 36.760 & 8.578 \\
\hline Águas Frias & 10.282 & 2.399 \\
\hline Bom Jesus do Oeste & 8.347 & 1.948 \\
\hline Caibi & 32.374 & 7.554 \\
\hline Campo Erê & 43.408 & 10.129 \\
\hline Caxambu do Sul & 14.984 & 3.496 \\
\hline Chapecó & 2.117 .479 & 494.079 \\
\hline Cordilheira Alta & 27.609 & 6.442 \\
\hline Coronel Freitas & 52.843 & 12.330 \\
\hline Cunha Porã & 65.354 & 15.249 \\
\hline Cunhataí & 7.969 & 1.860 \\
\hline Flor do Sertão & 4.683 & 1.093 \\
\hline Formosa do Sul & 11.045 & 2.577 \\
\hline Guatambú & 20.271 & 4.730 \\
\hline Iraceminha & 14.983 & 3.496 \\
\hline Irati & 3.511 & 819 \\
\hline Jardinópolis & 6.560 & 1.531 \\
\hline Maravilha & 214.954 & 50.156 \\
\hline Modelo & 25.243 & 5.890 \\
\hline Nova Erechim & 41.092 & 9.588 \\
\hline Nova Itaberaba & 18.160 & 4.237 \\
\hline Novo Horizonte & 8.254 & 1.926 \\
\hline Palmitos & 90.278 & 21.065 \\
\hline Pinhalzinho & 205.809 & 48.022 \\
\hline Planalto Alegre & 15.001 & 3.500 \\
\hline Quilombo & 49.893 & 11.642 \\
\hline Saltinho & 13.785 & 3.217 \\
\hline Santa Terezinha do Progresso & 4.876 & 1.138 \\
\hline Santiago do Sul & 5.070 & 1.183 \\
\hline São Bernardino & 6.424 & 1.499 \\
\hline São Carlos & 75.011 & 17.503 \\
\hline São Lourenço do Oeste & 173.070 & 40.383 \\
\hline São Miguel da Boa Vista & 4.689 & 1.094 \\
\hline Saudades & 59.638 & 13.916 \\
\hline Serra Alta & 17.269 & 4.029 \\
\hline Sul Brasil & 8.982 & 2.096 \\
\hline Tigrinhos & 4.285 & 1.000 \\
\hline União do Oeste & 9.050 & 2.112 \\
\hline
\end{tabular}

O município de Chapecó é o que concentra o maior número de habitantes da região, segundo valores do IBGE, cerca de 186.336 de habitantes o que também requer um grande aterro para suprir suas necessidades. Chapecó é bem localizada e bem plana com locais que podem ser implantado o aterro que suporte as necessidades de sua população, sendo necessários 
mais estudos técnicos para determina o melhor lugar (de Aquino, 2018), já que o município se encontra acima do aquífero Guarani e apresenta aeroporto em sua região, uma técnica que facilita essa escolha pode ser encontrada em Norese (2006) que utiliza sistemas de informações geográficas como ferramenta para determinar áreas de aterro sanitário.

O valor médio do tamanho dos aterros da região não é um bom parâmetro avaliativo dos resultados obtidos, haja visto, que só o município de Chapecó corresponde por $47 \%$ dos habitantes da região necessitando de um aterro de quase $500 \mathrm{mil} \mathrm{m}^{2}$, enquanto os demais municípios com populações variando entre 1.500 e 23.000 habitantes, exigindo no máximo uma área com 50 mil m² cerca de 10 vezes menor o que requer em área um aterro sanitário para uma cidade do porte que Chapecó. Segundo Barbosa et al (2020) essas diferenças entre cidades em uma mesma região é um dos principais problemas para a implantação de um consorcio intermunicipal para coletas de RSUs.

Com a área a ser ocupada pelos aterros variando entre $819 \mathrm{~m}^{2}$ a $494.076 \mathrm{~m}^{2}$ dentro dos municípios da região mostra a dificuldade da implantação das parcerias entre municípios que exige além de saber o tamanho da área necessária uma visão sistêmica da cadeia dos resíduos como preconiza Calderon (2018) e segundo Fulgêncio (2009) cada caso deve ser avaliado de um ponto de vista único e exclusivo ficando a cargo do poder público viabilizar os estudos necessários para a localização de áreas que suportem suas necessidades.

\section{Considerações Finais}

Os resíduos sólidos urbanos vêm se tornando um dos grandes problemas da sociedade moderna, que vem crescendo e se concentrando em grandes centros tornando a gestão do RSU um enorme desafio para o poder público, que desde 2014 vem tentando se adequar à lei $\mathrm{N}^{\circ} 12.305 / 2010$, gerir aterros cada vez maiores, o que em alguns casos pode chegar a ocupar quase $2 \%$ da área do município.

No caso de Chapecó, que apresenta o que seria o maior aterro da região com quase $500 \mathrm{mil} \mathrm{m}^{2}$, ocuparia aproximadamente $1 \%$ da área do município, que é pouco maior que $624 \mathrm{~km}^{2}$.

A união de alguns municípios em um consórcio para gerir um único aterro que dê suporte às suas necessidades é uma opção, sendo necessário um estudo mais aprimorado para implantação do aterro, como exemplo o de logística para que todos os municípios consorciados possam depositar seus RSUs com custos equitativos de tempo e dinheiro.

\section{Referências}

ABRELPE (2008 a 2017). Panorama dos Resíduos Sólidos no Brasil 2008 a 2017. Associação Brasileira de Empresas de Limpeza Pública e Resíduos Especiais.

IBGE (2010) - Instituto Brasileiro de Geografia E Estatística. Censo 2010.

ABNT - Associação Brasileira de Normas Técnicas -ABNT. (1984) Apresentação de projetos de aterros sanitários de resíduos sólidos urbanos Procedimento. NBR-8419/84. São Paulo, 13p.

Barbosa, G. T., de Souza, G. R., Ribeiro, A. G. C., Sant’Anna, L. T., \& Franco, C. S. (2020). Aterros Sanitários Municipais X Consórcios Públicos: a viabilidade econômica do CONSANE. Sustentare, 4(1), 61-72.

Calderan, T. B. (2018). Consórcios intermunicipais: condições e possibilidades de atendimento da Política Nacional de Resíduos Sólidos (PNRS) a partir do princípio da visão sistêmica.

Denardin, G. P. (2013) Estudo dos recalques do aterro sanitário da central de resíduos do Recreio - Minas do Leão/RS. 2013. 93 f. Dissertação (Mestrado) Curso de Engenharia Civil, Universidade Federal de Santa Maria, Santa Maria.

de Aquino, J. N. (2018). Uso de técnicas de modelagem e análise espacial na seleção de áreas ideais para construção de aterros sanitários em regiões metropolitanas densamente povoadas. Dissertação (Mestrado). 73 págs. Universidade Federal de Minas Gerais.

Dziekaniak, T. S. (2014). Política nacional dos resíduos sólidos: novos instrumentos legais com vistas ao desafio do manejo dos resíduos sólidos.

Fulgêncio, A.G. (2009) O Aterro Sanitário Intermunicipal de Quissamã-RJ: Uma reflexão sobre os instrumentos legais pertinentes à gestão de resíduos em pequenos municípios. Boletim do Observatório Ambiental Alberto Ribeiro Lamego, Campos dos Goytacazes/RJ, 3(2), 91-108. 
Research, Society and Development, v. 10, n. 11, e395101119803, 2021

(CC BY 4.0) | ISSN 2525-3409 | DOI: http://dx.doi.org/10.33448/rsd-v10i11.19803

Jacobi, P. R., \& Besen, G. R. (2011). Gestão de resíduos sólidos em São Paulo: desafios da sustentabilidade. Estudos avançados, 25, 135-158.

Jucá, J. F. T. (2003) Disposição final dos resíduos sólidos urbanos no Brasil. In: V CONGRESSO BRASILEIRO DE GEOTECNIA AMBIENTAL. Anais. Porto Alegre: REGEO, p. 443-470.

Meireles, S. (2012). Ferramenta de apoio a regulamentação técnica dos servidores públicos de limpeza urbana e manejo dos resíduos sólidos urbanos de Santa Catarina. Florianópolis, 2012, 145 p. Trabalho de Conclusão de Curso - Universidade Federal de Santa Catarina, Florianópolis

Norese, M. F. (2006) ELECTRE III as a support for participatory decision-making on the localization of waste-treatment plants. Land Use Policy, v. 23, p. 7685 .

Pereira A. S.; Shitsuka, D. M.; Parreira, F. J., \& Shitsuka, R. (2018). Metodologia da pesquisa científica. [e-book]. Santa Maria, RS: Ed. UAB/NTE/UFSM. Recuperado de https://repositorio.ufsm.br/bitstream/handle/1/15824/Lic_Computacao_MetodologiaPesquisa Cientifica.pdf?sequence=1.

Peron, C. C. (2019) As contribuições da reciclagem para o desenvolvimento sustentável: estudo de caso na cooperativa dos recicladores de Penápolis-SP (CORPE). Pag. 170. Universidade de Araraquara. Araraquara-SP

Picchiai, D., \& Senigalia, F. (2019). Gestão de Resíduos Sólidos Integrada às Responsabilidades das Micro e Pequenas Empresas e do Poder Público Municipal. Desenvolvimento em Questão, 17(49), 112-135.

Russo, M. A. T. \& Vieira, J. M. (2006). Avaliação da estabilização de RSU em aterro através da evolução da degradabilidade da sua facção orgânica. In: ed. lit. - "Planeamento estratégico em águas e resíduos: actas do Encontro Nacional de Saneamento Básico, 12, Cascais, Portugal, 2006" [CD-ROM]. Cascais : APESB

Silva, C. C. (2017). Representação social do trabalho de catação de material reciclável: catadores e catadoras do lixão de Furna da Onça, Esperantina (PI).

Silva, K. T. da. (2016) Projeto de um aterro sanitário de pequeno porte. 2016. 97 f. TCC (Graduação) - Curso de Engenharia Civil, Universidade Federal do Rio de Janeiro, Rio de Janeiro.

Silva, X.J. \& Zaidan, T.R. (2004) Geoprocessamento e análise ambiental: aplicações. Rio de Janeiro: Bertrand Brasil, 368 p.

Souza, Helio A. (2002) Métodos e técnicas aplicados na avaliação ambiental do aterro da BR-040 da Prefeitura Municipal de Belo Horizonte - MG; REM: $R$. Esc. Minas, Ouro Preto, Pag.: 291-300 